\title{
ENTRE LA AGRICULTURA Y EL TRABAJO URBANO: DOS ESTUDIOS DE CASO EN la Periferia de Xalapa, una CIUdAd Media del estado de Veracruz (México)
}

\author{
Between Agriculture and Urban Activities: Two Case Studies in the Surrounding Countryside of Xalapa, \\ a Middle-Sized Town of the State of Veracruz (Mexico)
}

\author{
Virginie Thiébaut \\ Emilia Velázquez-Hernández
}

\begin{abstract}
Resumen: Eneste trabajo se estudian las relacionesentreciudady campoy su impactoen los paisajesen dos localidades de laperiferiade Xalapa, Veracruz. En el siglo XX, los habitantes de localidades rurales, sobre todo de la periferia de ciudades importantes, complementaban los ingresos del campo diversificando sus actividades, fenómeno que se reforzó en los ochenta y noventa con la crisis del sector agropecuario. Se estudia la relación con Xalapa de dos localidades de su periferia: Chavarrillo y Tlalnelhuayocan. Podremos ver que la pluriactividad y las relaciones con la ciudad adoptan formas distintas y que las consecuencias en los paisajes varían en relación con las características naturales, socioeconómicas y culturales de cada localidad.
\end{abstract}

Palabras clave: diversificación económica, relaciones campo-ciudad, periferia, ingresos.

Abstract: This paper studies the relations between rural and urban areas, and the impact that their evolution has had on landscapes in two localities on the outskirts of Xalapa, capital of the state of Veracruz. Mexico. Throughout the twentieth century, people in rural communities, especially those living on the periphery of major cities, have supplemented their farm incomes by diversifying their activities, a phenomenon reinforced and accentuated during the eighties and nineties with the crisis of the agricultural sector. Our study addresses the relationship between the city of Xalapa and two outlying localities: Chavarrillo and Tlalnelhuayocan. The study shows that the multiple activities and relations that each locality establishes with the city can take different forms, and that the consequences for landscapes vary in relation to the natural, socioeconomic and cultural features of each locality.

Keywords: economic diversification, rural-urban relations, outskirts, incomes.

\footnotetext{
Virginie Thiébaut. Doctora en Geografía Humana por la Universidad de Nancy 2, Francia. Investigadora-docente del Instituto de Investigaciones Históricos Sociales, de la Universidad Veracruzana, México. Temas de especialización: evolución de los paisajes rurales, en especial los paisajes cañeros; percepción de los paisajes. Correo electrónico: virginiathiebaut@yahoo.fr.

Emilia Velázquez Hernández. Doctora en Ciencias Sociales por El Colegio de Michoacán, México. Profesora-investigadora en el Centro de Investigaciones y Estudios Superiores en Antropología Social (CIESAS), sede Golfo, México. Temas de especialización: cambios en las formas de acceso y propiedad de la tierra, migración interna derivada del impacto de las políticas neoliberales en el medio rural. Correo electrónico: emivel@ciesas.edu.mx.
}

Enviado a dictamen: 7 de abril de 2016 Aprobación: 25 de septiembre de 2016. Revisiones: 1 . 


\section{Introducción}

$\amalg$ n las últimas dos décadas, diversas investigaciones han dadocuentadelasprofundastransformaciones que han ocurrido en el campo mexicano a causa principalmente de las políticas neoliberales que empezaron a aplicarse en la década de 1980. ${ }^{1}$ En algunos trabajos se ha enfatizado la relación entre el declive de la producción agrícola y de los mercados regionales de trabajo, con el desarrollo de prácticas migratorias -internacionales y nacionales - hasta entonces desconocidas en las regiones de estudio (por ejemplo, Mestries, 2003; Velázquez, 2013); en otros se ha indagado sobre diferentes aspectos relacionados con las transformaciones en los mercados de trabajo agrícola y la organización flexible del trabajo (Lara Flores, 1998 y 2010); algunos más se han centrado en analizar los cambios en los patrones de cultivo como respuesta a la decadencia de las actividades agrícolas que habían sido predominantes en la región (Espinoza-Ortega, 2005; Thiébaut, 2012); y en otros se ha reflexionado sobre las limitaciones de ciertas categorías para dar cuenta de las nuevas condiciones en las que se vive y trabaja en el medio rural (por ejemplo, Arias, 2009a).

En este contexto, la investigación que aquí presentamos busca contribuir a la discusión sobre las condiciones en las que se reproducen las sociedades rurales en un contexto de profundización de la crisis económica en los diferentes sectores productivos. En lo particular, nos preguntamos sobre las estrategias productivas y de trabajo de familias que residen en asentamientos rurales ubicados en la periferia de una ciudad media - Xalapa, Veracruz - cuya economía se centra en la prestación de servicios - comercio, salud, educación-. Para ello, elegimos dos localidades, Chavarrillo y San Andrés Tlalnelhuayocan, en las que, por un lado, todavía es notable la actividad agrícola y, por otro, sus habitantes tienen la ciudad de Xalapa como sede principal de sus fuentes de trabajo no agrícola (ver mapa l).

Nuestras preguntas de investigación, así como las explicaciones a las situaciones empíricas que hemos descubierto en nuestro trabajo de campo, las hemos construido en diálogo con algunos de los planteamientos y conceptos desarrollados en el marco de los estudios sobre la nueva ruralidad. Desde este enfoque se ha planteado que, para enfrentar la crisis productiva causada por los bajos precios de las cosechas, los altos costos de producción, la carencia de asesoría técnica y la inexistencia de créditos a la producción, la gran mayoría de los hogares campesinos en México ha debido intensificar la pluriactividad para obtener ingresos de fuentes alternas a la agricultura (Appendini, 2008; Carton de Grammont, 2009a), lo que ha llevado a hablar de un proceso de "desagrarización" del campo mexicano. ¿Un planteamiento de este tipo significa que hay un proceso, lento o acelerado, pero continuo e irreversible de abandono de las actividades agrícolas o que, al contrario, el hecho de multiplicar las actividades es una manera de mantener activo el sistema de producción mediante la adquisición de ingresos salariales complementarios? Esta es la pregunta central que orientó nuestro trabajo de investigación.

La pluriactividad rural ha sido definida como "la combinación de por lo menos dos actividades, siendo una de éstas la agricultura" (Schneider, 2009: 210). Esta diversificación de actividades, en la que juega un papel especial el trabajo asalariado no agrícola, tiene como objetivo estabilizar los ingresos de los hogares rurales, afectados por la pérdida de viabilidad económica y la desvalorización social de las labores campesinas (Arias, 2009b). Si bien la pluriactividad siempre ha existido en el medio rural, ésta se ha reforzado en las últimas décadas como consecuencia de la reorganización internacional del mercado de productos agropecuarios (Schneider, 2009; Barkin, 2013). Así, las sociedades rurales han transitado por un proceso caracterizado por dos eventos principales: el crecimiento de los ingresos no agrícolas y, en paralelo, la pérdida de centralidad de la actividad agropecuaria como eje articulador de la vida económica, social y cultural (Carton de Grammont, 2009b; Salas y Rivermar, 2011).

Los estudios realizados en distintas partes de América Latina evidencian la existencia de numerosas formas de pluriactividad, con una gran variedad de combinaciones posibles, según los países, el contexto 
local y regional, y también los cambios en el mercado del trabajo y el acceso a los mercados internacionales (Carton de Grammont y Martínez, 2009). Las consecuencias de la pluriactividad también pueden ser diversas, ya sea permitir simplemente la supervivencia de la familia rural, posibilitar la acumulación y desarrollo de capacidades empresariales, o propiciar el abandono de la actividad agrícola (Schneider, 2009: 209; Kay, 2016: 17). Cualesquiera que sean sus causas, la pluriactividad se ha convertido en uno de los rasgos centrales de la nueva ruralidad (Schneider, 2009: 213). Ésta se caracteriza además por un proceso cada vez más marcado de desvinculación de una parte de la población rural de las actividades agropecuarias, y por el aumento en el número de habitantes de áreas rurales que se dedican exclusivamente a actividades no agrícolas ruralidad sin agricultura-.

La desarticulación de las formas "tradicionales" de organización familiar y comunitaria y el deterioro del medioambiente han sido algunas de las consecuencias de esta alteración de la ruralidad (Salas y Rivermar, 2011). Otra ha sido el debilitamiento de las fronteras entre los medios rural y urbano por motivos como: la movilidad constante de los habitantes rurales que se dirigen a la ciudad por razones laborales, comerciales o en búsqueda de servicios; el desarrollo de los servicios y de las infraestructuras — vías de comunicación, medios de transporte - en las zonas rurales, y los cambios importantes de usos de suelo provocados por la expansión urbana con la colonización de áreas rurales periféricas y la consecuente transformación de actividades - ruralidad urbanizada - lo que ha trastocado de manera definitiva las relaciones entre lo urbano y lo rural (Méndez, 2009; Martínez y Vallejo, 2011).

A partir de este tipo de planteamientos llevamos a cabo la investigación cuyos resultados exponemos en este artículo. Nuestras reflexiones se sustentan en la información recabada en 41 entrevistas a profundidad que realizamos a, cuando menos, un miembro de un hogar rural. El levantamiento de información lo llevamos a cabo entre abril y diciembre de 2015 en las dos localidades de estudio. Consideramos como unidad de análisis el hogar, o sea, el establecimiento donde viven los miembros de una misma familia, y seleccionamos los hogares de manera aleatoria, buscando obtener cierta diversidad en cuanto a la edad del entrevistado y su actividad principal. En las entrevistas, obtuvimos información sobre los distintos miembros de la familia, referida tanto al presente como a décadas anteriores. Para diseñar las entrevistas de campo, así como para analizar la información recabada, retomamos las categorías de análisis propuestas por Hubert Carton de Grammont (2009a) para diferenciar los hogares que viven de actividades agropecuarias, combinadas muchas veces con otro tipo de actividades, de los que viven solamente del trabajo asalariado. Las primeras son las Unidades Económicas Campesinas Pluriactivas, y las segundas son las Unidades Familiares Rurales.

El artículo está dividido en tres apartados. En el primero de ellos mostramos las características generales tanto de la ciudad de Xalapa, como de las dos localidades de estudio. En el segundo y tercer apartados nos centramos en analizar con detalle las Unidades Económicas Campesinas Pluriactivas y las Unidades Familiares Rurales para cada uno de los lugares de estudio y la evolución particular que en cada una de ellas ha tenido la pluriactividad.

\section{Ubicación y evolución histórica de las localidades de estudio}

\section{La expansión de Xalapa y la conformación de un área metropolitana diversa}

Para entender la evolución de las dos localidades de estudio, es muy importante describir brevemente las características de la capital del estado y entender el contexto de crecimiento de la misma y su dinámica de expansión a lo largo del siglo XX. Estos son factores que, junto con el deterioro de las condiciones para la producción agrícola, han impactado sobre la zona de influencia urbana y las dinámicas de las relaciones campo-ciudad.

Si bien en los siglos XVIII y XIX Xalapa experimentó un crecimiento demográfico y territorial moderado, pese a su ubicación estratégica en la ruta que unía el puerto 
de Veracruz con la Ciudad de México, dicha situación cambió a lo largo de la primera mitad del siglo XX. Según Villanueva (2011: 132), en el período transcurrido entre 1921 y 1950 el crecimiento poblacional de la ciudad de Xalapa fue del 3\% anual aproximadamente, un porcentaje mayor que el registrado para el estado de Veracruz en su conjunto entre 1910 y 1930, que fue del $0.98 \%$. En números absolutos, la población de Xalapa pasó de 20388 habitantes en 1900, a 51169 en 1950 (INEGI, Archivo Histórico de Localidades); este crecimiento demográfico acelerado continuaría durante la segunda mitad del siglo XX y la primera década del siglo XXI. Así, por ejemplo, en las décadas de 1970 y 1980 el crecimiento anual de la población de Xalapa fue de $6.7 \%$ y $6.3 \%$ respectivamente, más del doble que el crecimiento de la población en el estado de Veracruz, que fue del 3\% (Villanueva, 2011: 132). Esta dinámica de crecimiento demográfico se mantuvo en las siguientes décadas, de tal manera que la población se duplicó entre 1980 y 2010, pasando de 204594 habitantes a 424755 (INEGI, Archivo Histórico de Localidades, 1980 y 2010), con la consiguiente demanda de servicios y viviendas.

La superficie urbana creció de manera casi proporcional al aumento de población, pasando de cubrir 643 hectáreas en 1950, a 6096 hectáreas en 2010 (Marchal, 1985: 142; Palma, información oral). Desde 1950, las zonas de crecimiento más fuertes estaban ubicadas en el norte y sureste de la ciudad, siguiendo el eje de comunicación central Xalapa-Veracruz, mientras, de manera menos acentuada, la urbanización se extendía también a lo largo de los ejes secundarios: las carreteras a Coatepec, El Castillo y Tlalnelhuayocan. En las últimas décadas, la expansión siguió los mismos ejes, pero se hizo mediante la integración de puntos aislados al incorporar viejos asentamientos conurbados y crear nuevos fraccionamientos; unos y otros fueron absorbidos paulatinamente por el área metropolitana —como fue el caso de Banderilla, El Lencero y Dos Ríos, entre otros-.

La zona metropolitana de Xalapa incluye en la actualidad siete municipios - Xalapa, Coatepec, Banderilla, Emiliano Zapata, Tlalnelhuayocan, Jilotepec y Rafael Lucio-, según el Consejo Nacional de Población (CONAPO) y el Instituto Nacional de
Estadística, Geografía e Informática (INEGI), ${ }^{2}$ y cinco - los primeros citados - según el Plan de Desarrollo Municipal de Xalapa 2005-2007 (Acosta, 2011: 39). En cualquier caso, la zona metropolitana, muy extendida, está conformada por una multitud de localidades rurales y urbanas y presenta una gran diversidad de actividades y de población.

De forma general, se pueden distinguir dos grandes subzonas en esta zona metropolitana, con rasgos topográficos, trayectorias históricas y características socioeconómicas, culturales y poblacionales distintas. Por un lado, la planicie que se extiende al sur de Xalapa, donde predominaban en la época colonial las grandes haciendas cañeras y ganaderas, y que en el siglo XIX adoptaron el cultivo del café, como La Orduña, Pacho Viejo, Tuzamapan y Mahuixtlán (Florescano, 1992). Por otra parte, y de manera contrastante, están los pueblos de origen indígena de la serranía del norte y noroeste, dedicados al cultivo de la milpa en terrenos accidentados y poco fértiles. En el primer caso, la producción comercial implicó la integración temprana a los mercados nacionales e internacionales y una conexión a las vías de comunicación que vinculaban el puerto de Veracruz con el altiplano - el camino real, y posteriormente el ferrocarril y las carreteras-. En el segundo, los pueblos se quedaron relativamente aislados hasta una época reciente, con el predominio de cultivos tradicionales de subsistencia y relaciones comerciales limitadas, orientadas casi exclusivamente a la capital del estado. Estas circunstancias implican unas trayectorias y dinámicas muy distintas hasta la actualidad, como mostraremos en los siguientes apartados.

\section{Chavarrillo: la formación de un pueblo ejidal cafetalero}

Chavarrillo, localidad situada en la planicie del sur de Xalapa, se formó tras la división de la hacienda ElEncero, ${ }^{3}$ cuando Nicolás Contreras adquirió una extensión de 806 hectáreas, las cuales se extendían por el cerro de Tepeapulco y el llano de Nevería. En el siglo XIX, se practicaban en estas tierras las mismas actividades que en las grandes haciendas que la rodeaban: la ganadería 
bovina extensiva y el cultivo de la caña de azúcar, que se procesaba en un pequeño trapiche situado en el pueblo. Había además pequeñas superficies de cultivo de tabaco, yuca y café — cultivo que apareció al final del siglo XIXy producciones destinadas al autoconsumo, como el maíz (Casas, 1993: 150-155). Una actividad complementaria era la alfarería orientada a la confección de moldes para la elaboración de piloncillo, que se vendían al trapiche de la vecina hacienda Tuzamapan; también se fabricaba material de construcción - tejas, pisos de ladrillo y tabiques - que se comercializaba a nivel regional, utilizando para ello un depósito de barro de gran calidad que había en la hacienda.

A inicios de la década de 1930, los trabajadores de los Contreras, participantes activos del movimiento agrarista veracruzano, obtuvieron la dotación de 764 hectáreas, conformándose así el ejido Chavarrillo. ${ }^{4}$ Desde el inicio, los ejidatarios, liderados por Josafat Ruiz, optaron por una organización incluyente del nuevo ejido, con la atribución de fracciones de tierras ejidales a personas sin derechos agrarios - hijos de ejidatarios y posesionarios llegados de fuera-. Esta asignación local de tierra ejidal se otorgaba de acuerdo con las necesidades de los solicitantes y sólo era condicionada al respeto de ciertas pautas establecidas por los ejidatarios - buena conducta, lealtad al ejido y participación en los trabajos para beneficios colectivos acordados en asamblea (Casas, 1993: 181) - .

Los 76 ejidatarios poseían un derecho agrario para cultivar diez hectáreas de tierra, aunque no lograron explotar tal superficie por las condiciones topográficas del terreno y la falta de mecanización. La atribución de tierra a ejidatarios y posesionarios se hizo de manera progresiva en el tiempo: cada campesino recibió una o dos hectáreas en distintas fracciones del ejido. Tal distribución dispersa tuvo como consecuencia la multiplicación de los trayectos para los campesinos, pero permitió también cierta diversificación y complementariedad de los cultivos por las condiciones distintas de suelo, clima, etcétera. La barranca, por ejemplo, zona de difícil acceso situada a dos kilómetros al este del pueblo, con suelos muy fértiles, se cultivó intensivamente con el auge del café, a partir de los años cincuenta, ya que la zona presentaba las características ideales para tal cultivo — sombra, humedad, fertilidad-. Se plantó también en esta zona más árboles de mango, cultivo comercial importante entre los años sesenta y ochenta, y plátano roatán. La loma, montículo volcánico situado al pie del cerro Tepeapulco, convenía para la siembra de maíz y frijol y para productos de autoconsumo, como el tomate y el pepino. Después de efectuadas las cosechas, el mismo terreno se utilizaba como potrero de uso común para pastoreo de los animales - caballos, mulas, vacasCuando el café empezó a tener un precio más alto, en los años sesenta, y a ser un producto de exportación importante, los cafetales ganaron terreno poco a poco sobre los cultivos de subsistencia, que quedaron reducidos a pequeñas superficies. Esto ocurrió también en otras zonas de cultivo, como la orilla del río.

Al final de los años ochenta y principios de los noventa, la caída del precio del café, y el posterior cierre de la paraestatal INMECAFÉ (Instituto Mexicano del Café), llevaron al desplazamiento de los cafetales por huertas de limón, presentes en pequeñas superficies en la región desde el final de los años cuarenta. Los limonares se fueron intercalando poco a poco entre los cafetales, hasta volverse mayoritarios cuando se instalaron empacadoras de limón en la localidad y se empezó a cultivar este producto para exportación a finales de los años noventa; subsistieron solamente matas de café en manchones aislados y en las orillas de las parcelas. Como el limón se puede plantar en suelos áridos y pedregosos, se fueron intensificando las zonas de cultivo en los alrededores del pueblo y del río; "hicieron servir tierras que no servían antes", como comentó un campesino. En losúltimos años, la plaga de la roya ha acelerado aún más la reducción de los cafetales.

\section{Tlalnelhuayocan: un pueblo prehispánico con actividades tradicionales}

Tlalnelhuayocan es un pueblo de origen prehispánico, poblado por totonacas y posteriormente por nahuas, que obtuvo en los siglos XVI y XVII varias mercedes de tierra por parte del virrey de España (AGEV, CAM, 
exp. 93). En las décadas de 1930 o 1940 del siglo XIX, la comunidad vendió el Potrero San Andrés —en el cual se extendía gran parte de sus tierras de cultivo- a la hacienda Lucas Martín, conocida por aumentar su propiedad mediante el despojo de tierras a los indios y las ventas forzadas (León, 2009: 63-64). Más de un siglo después, la descripción que se hacía del poblado San Andrés Tlalnelhuayocan, ${ }^{5}$ y el censo de los agricultores que solicitaban la dotación de un ejido, elaborado en 1925, permiten apreciar la situación de precariedad y pobreza en la cual vivía la población al inicio del siglo XX (AGEV, CAM, exp. 93). La mayoría de los solicitantes, agricultores y jornaleros, cultivaba un pedazo de tierra de menos de una hectárea, ya fuera de su propiedad, o arrendada a las haciendas Lucas Martín y La Orduña o a pequeños propietarios. El cultivo principal era el maíz y se menciona también la presencia de frijol en pequeñas superficies, ambas cosechas para el autoconsumo; pocos habitantes tenían animales. La única industria era la fabricación de carbón, y se vendían cargas de leña y de madera para la construcción, lo que se explica por la gran cantidad de bosque presente en estos terrenos escarpados.

La dotación provisional del ejido San Andrés, que se otorgó en 1925 con una superficie de 981 hectáreas, afectó a la hacienda Lucas Martín, y a tierras situadas a diez kilómetros al sur, cerca de la localidad Rancho Viejo - rancho La Yerbabuena, de los hermanos Juan y Rómulo Ramírez- ${ }^{6}$ El ejido, conformado por terrenos de temporal y de monte bajo y alto cultivables, quedó constituido por dos polígonos - actualmente conocidos como San Andrés y Rancho Viejo — correspondientes a las dos propiedades afectadas, entre los cuales quedaron insertas tierras de propiedad privada. Únicamente se benefició a 127 capacitados, quedando excluidos del reparto 472 solicitantes. Las parcelas de los ejidatarios quedaron divididas entre las dos fracciones expropiadas, aunque hubo casos de parcelas ubicadas en uno solo de los polígonos. Los beneficiados mantuvieron sus tierras "en común", es decir, sin la asignación formal de una parcela delimitada, y aunque la superficie máxima otorgada fue de ocho hectáreas, la mayoría cultivó solamente lo que la fuerza de trabajo familiar disponible permitía — menos de cuatro hectáreaspor lo quebrado del terreno. La propiedad privada que subsistió a la Reforma Agraria se encontraba igualmente muy fragmentada.

El reparto agrario no cambió radicalmentela situación de los campesinos ni solucionó tampoco los problemas de subsistencia. La superficie cultivable reducida de cada ejidatario, y las pocas posibilidades de diversificar las producciones a causa de las características topográficas y climáticas del lugar, hicieron que los campesinos se siguieran dedicando principalmente al cultivo de la milpa para autoconsumo y a la extracción de madera, aunque se desarrolló un poco la ganadería bovina. En la década de 1960 algunos campesinos empezaron a producir hortalizas en pequeñas superficies, cerca de sus casas, a veces en alternancia con el maíz, para diversificar y comercializar.

\section{Chavarrillo: evolución de la pluriactividad y cambios en los usos de suelo}

En el caso de Chavarrillo, la intensificación de la diversificación económica se explica por la disminución de la rentabilidad de la actividad agrícola ocasionada por la baja general de los precios de los productos del campo y los altos costos de producción a partir de los años ochenta y noventa, así como por el escaso o nulo apoyo del Estado a la producción agrícola, pero también por características específicas del ejido, como la gran dispersión de las fracciones que componen las parcelas y la posterior división de éstas entre los hijos de familias numerosas. Muchos de los habitantes poseen actualmente una extensión de tierra reducida - menos de tres hectáreas - , superficie que difícilmente permite la sobrevivencia de una familia, o no tienen acceso a la tierra. Este factor se combina con otros, fuertemente interrelacionados, como la cercanía de Xalapa, con su oferta laboral diversificada y múltiple, y la preferencia por las actividades urbanas por parte de los jóvenes. Sin embargo, pese a las condiciones adversas para la actividad agrícola, en Chavarrillo más de tres cuartas partes de los hogares cuentan con una finca ${ }^{7}$ en producción, ya sean 
ejidatarios, posesionarios y pequeños propietarios; son entonces Unidades Económicas Campesinas Pluriactivas, según la clasificación de Carton de Grammont (2009a). ${ }^{8}$

\section{Combinación de actividades variadas en las Unidades Económicas Campesinas Pluriactivas}

En estas Unidades existe una gran diversidad de situaciones. La finca puede ser la actividad principal para el jefe de familia, a nivel de ingresos y de tiempo invertido, o, más comúnmente, una actividad secundaria que complementa un trabajo asalariado, pero casi nunca se trata de una actividad única. Varios de los campesinos entrevistados completan los ingresos insuficientes obtenidos de su pequeña parcela trabajando en tierras ajenas del mismo ejido como jornaleros. Las opciones de contratarse de manera estable en una finca perteneciente a un habitante del pueblo que se dedica a otra actividad, a veces un familiar, son bastante comunes por la diversificación alta de las actividades y el número importante de personas que trabaja en los sectores secundario y terciario. El jornal que se paga en Chavarrillo es de los más altos en la región —-180 a 200 pesos diarios - y representa un ingreso, si no siempre más importante, por lo menos más constante, que el proveniente de la venta de café y limón de la finca. Por ejemplo, el señor Guillermo, de 46 años, cultiva una finca de una hectárea plantada con café y limón, la cual heredó de su padre cuando éste dividió su parcela entre sus seis hijos. Este hombre trabaja al mismo tiempo como jornalero en la finca de un vecino, Omar A., quien tiene un trabajo asalariado en la central nuclear de Laguna Verde. Guillermo se dedica la mayor parte del tiempo a la finca ajena, y sólo va a la suya los fines de semana, después del trabajo o algunos días que pide permiso a su patrón cuando hace falta chapear, cortar limón, etcétera. Sus 230 árboles de limón y 1500 matas de café le proporcionan aproximadamente diez toneladas de limón y dos de café al año, lo que, a pesar de la gran variabilidad de los precios del limón y la baja de rendimiento del café en los últimos años debido a la roya, le puede proporcionar de 45000 a 50000 pesos anuales de ingresos brutos, lo que equivale aproximadamente a lo que gana con su jornal durante un año (entrevista a GRV, Chavarrillo, 28 de junio de 2015).

Es importante mencionar que en algunas familias existe un acuerdo entre los hermanos para el mantenimiento de la finca, de tal forma que los que se dedican a actividades no campesinas contratan a sus hermanos para que hagan los trabajos necesarios para mantenerla en producción. Esto permite no sólo conservar cierta unidad entre varias fracciones de una parcela que se heredó del padre, sino también dar trabajo a los hermanos sin preparación escolar para que éstos no tengan que salir del pueblo, y que aquéllos dedicados a trabajos no agrícolas puedan mantener cultivada y en buen estado una finca. Un ejemplo de ello es el de los hermanos JB, quienes tienen entre 45 y 35 años: Sergio es contador en Xalapa, Marcos es empleado de la tienda Costco en la misma ciudad y Cristino es trabajador en la empacadora de limón Cítricos Arturín, situada en Chavarrillo. Ellos contratan a dos hermanos que se dedican exclusivamente al trabajo agrícola, quienes disponen tanto de las ganancias obtenidas de la venta de las producciones de sus propias fincas, como del salario que ganan por atender las fincas de sus hermanos (entrevista a SJB, Chavarrillo, 28 de junio de 2015).

Otros campesinos, además de emplearse temporalmente en tierras ajenas, tienen otras actividades que les permiten complementar los ingresos obtenidos de la parcela. Por ejemplo, el señor Jesús C., de 60 años, posee una pequeña granja de lechones, se dedica a la cría de bestias y vende los almácigos de limón que cultiva en un vivero junto con un socio (entrevista a JC, Chavarrillo, 3 de junio de 2015). Las labores complementarias pueden estar también vinculadas al sector secundario y terciario y ejercerse dentro o fuera del pueblo. Una actividad complementaria de la agrícola que se ha mantenido en el pueblo desde la época de los hacendados es la alfarería y la elaboración de material de construcción. Varias familias tienen sus galerías en la entrada del pueblo, y combinan la fabricación 
de tabiques, mazarines, soleras y tejas con el cuidado de la parcela. El señor Domingo, ejidatario de 79 años, se dedica a las dos actividades desde que empezó a trabajar, hace más de sesenta años. En conjunto con su hijo Josafat, organiza sus actividades diarias según los pedidos de material de los clientes y las necesidades de las parcelas (entrevista a DRJ, Chavarrillo, 29 de mayo de 2015).

En Chavarrillo se desarrolló también una actividad agroindustrial con la aparición de tres empacadoras de limón entre 1999 y 2010. La más importante, Cítricos Arturín, que exporta directamente a Estados Unidos, emplea a sesenta personas, entre peones de las huertas, trabajadores de la bodega, administrativos y choferes. La otra empacadora, que vende al mercado nacional - Mercado de Abastos de la ciudad de Xalapa y supermercados Chedraui- y a empacadoras de cítricos de Martínez de la Torre para su posterior exportación, contrata a veinte personas. Otra, que es de los ejidatarios, está ahora rentada - Inverafruty exporta por temporadas a Europa. Varios de los trabajadores combinan el trabajo asalariado en las empacadoras con las labores en su finca, aunque sus condiciones laborales no les permiten dedicar tiempo suficiente a la atención de sus huertas. ${ }^{9}$ César, por ejemplo, trabajador de Cítricos Arturín, cuidó su parcela en combinación con otras actividades durante años, pero desde que entró a trabajar a la empacadora, por falta de tiempo encarga a sus dos hermanos mayores la atención a su parcela (entrevista a CFD, Chavarrillo, 17 de junio de 2015).

Muchos de los jóvenes - hayan estudiado en la Universidad ${ }^{10}$ o no- trabajan fuera de la localidad, en Xalapa, o a veces más lejos - Veracruz, Central Nuclear Laguna Verde-, mayormente en el sector terciario, en servicios y comercios. Hijos de ejidatarios y posesionarios, no han querido o podido dedicarse a la parcela porque tienen otros intereses o porque no tienen acceso a la tierra o a una superficie suficiente, pero los que heredan deciden conservar las hectáreas a pesar de ejercer otro oficio, como se vio en el caso de Omar A., trabajador de Laguna Verde, que contrata a diario a un jornalero para cuidar sus plantaciones de limón.
En las Unidades Económicas Campesinas Pluriactivas existe entonces una amplia gama de posibilidades que permite combinar actividades diversas con la agrícola. Es importante resaltar que, a pesar de que en muchos casos la finca es sólo un complemento a un trabajo asalariado estable que proporciona la parte más importante de los ingresos, las personas siguen encontrando los mecanismos para que se cultive la parcela y no se quieren deshacer de ella.

\section{Las Unidades Familiares Rurales, el arraigo de los trabajadores de la ciudad a la comunidad}

Solamente una cuarta parte de los hogares de Chavarrillo no tiene acceso a la tierra por diversas causas: han carecido de ella por varias generaciones, en algún momento decidieron deshacerse de su propiedad, o son jóvenes que no tienen acceso a la tierra y están totalmente desvinculados del sector primario porque la parcela sigue en manos de su padre. Un caso es el de Guadalupe, de 57 años, hijo de ejidatario. Este señor era posesionario pues obtuvo de su padre tres hectáreas en el año 1977. Después de trabajar varios años con su padre y luego en su propia finca, Guadalupe empezó en 1980 a dedicarse de tiempo completo al comercio. Multiplicó las experiencias laborales en varios negocios de Xalapa, y en 1995 decidió dividir la parcela — que no cuidaba personalmente desde hacía años - y heredarla a sus tres hijos. Estos vendieron sus tierras muy pronto, tanto porque tienen otros oficios - uno es policía en Veracruz, otro tiene un pequeño taller de electrónica en un mercado de Xalapa, y la hija, divorciada, se dedica al hogar-, como porque carecen de interés por el campo (entrevista a GRV, Chavarrillo, 21 de junio de 2015).

Otro caso es el del señor José C., de 48 años, hijo de ejidatario, que desde el año 1990 se dedica exclusivamente a la producción y venta de alfarería. Después de haber laborado varios años en la parcela de su padre y en tierras ajenas, a la edad de 23 años decidió dedicarse sólo a la fabricación de cerámica, actividad secundaria de su padre. Dos factores coincidieron en 
su toma de decisión: tuvo serios problemas de salud debido al uso de agroquímicos en el campo y la demanda de piezas de alfarería aumentó (entrevista a JCV, Chavarrillo, 3 de junio de 2015).

En cuanto a los jóvenes, un número considerable de ellos trabaja fuera de la localidad, sin ningún vínculo ya con el campo por la pérdida de rentabilidad de la actividad, la falta de acceso a una superficie de tierra suficiente y el exceso de trabajo y esfuerzo que representa. Sin embargo, muchos de ellos decidieron quedarse a vivir en el pueblo, lo que dio más peso al fenómeno de "ruralidad sin agricultura". El corto tiempo de recorrido a Xalapa ${ }^{11}$ y la facilidad para dirigirse desde allí hacia otros puntos representan una ventaja para los movimientos diarios. Por otro lado, permanecer en la comunidad de origen les ofrece otros beneficios, como el acceso a un solar que les proporcionan sus padres y facilidades para construir una casa. Además, como resalta Patricia Arias al estudiar la nueva ruralidad en espacios metropolitanos (2005: 148), los jóvenes que se quedan en su localidad de origen conservan así las relaciones comunitarias. En Chavarrillo, el sentido de comunidad — realización de faenas, cooperación de todo el pueblo en caso de fallecimiento, participación en las festividades, etcétera- y el arraigo a la localidad siguen siendo especialmente fuertes. No faltan, sin embargo, los casos de migración definitiva por cuestiones laborales, siendo los destinos principales las ciudades de Xalapa, Veracruz, y México; hay también algunos casos de migración a Estados Unidos.

\section{La pluriactividad y su evolución en el tiempo en Chavarrillo}

Es muy importante señalar que la división entre Unidades Económicas Campesinas Pluriactivas y Unidades Familiares Rurales, debida a la diversificación de las actividades y al recurso al trabajo asalariado, no es ninguna novedad, como ha sido señalado para otras regiones (Appendini, 2008). En Chavarrillo, una pequeña parte de los habitantes se dedicó a actividades no campesinas desde la época de la hacienda de los Contreras - primeras décadas del siglo XX-
La historiadora Rosa Catalina Sánchez (1979: 174175) calcula que, en los años veinte, en los pueblos vecinos - La Estanzuela y El Chico- el 9\% de los habitantes practicaba oficios ajenos a la agricultura. La situación debía ser muy parecida en Chavarrillo, donde había artesanos que elaboraban alfarería y algunos comerciantes.

Cuando se formó el ejido, diversas condiciones - el fraccionamiento de las parcelas en varias fracciones, la condición difícil del terreno y la ausencia de cultivos económicamente rentables - provocaron que muchos de los ejidatarios y de los posesionarios con acceso a la tierra se dedicaran de manera temporal o permanente a otras actividades. Don Emelio, nacido en 1925, nos contó cómo a pesar de ser ejidatario con título y parcela desde 1949, tuvo que trabajar en la Comisión Municipal de Agua Potable de Xalapa durante siete años, como ayudante de un ingeniero topógrafo, al final de los años cincuenta; fue ésta la única manera de mantener a sus doce hijos porque no obtenía de su parcela ni los ingresos ni los alimentos suficientes. Fue solamente cuando el café empezó a ser un cultivo rentable, en los años sesenta, cuando don Emelio regresó a vivir al pueblo y se dedicó únicamente a su parcela (entrevista a ERR, Chavarrillo, 10 de junio de 2015).

Otros campesinos tenían trabajos asalariados en el pueblo para complementar los ingresos obtenidos de la venta de los productos agrícolas; laboraban en las galeras de material de construcción en obras temporales, como la construcción de los túneles para el nuevo trazado de la vía de ferrocarril en los años sesenta y setenta, ${ }^{12}$ o en tierras ajenas como jornaleros. Hubo también numerosos casos de migración definitiva, sobre todo a Xalapa, por parte de hermanos e hijos de ejidatarios que no tenían acceso a la tierra y buscaron oportunidades de trabajo en otros lados ya que las opciones dentro de la localidad eran limitadas.

Si el trabajo asalariado y la migración temporal o definitiva no constituyen una novedad, existen sin embargo diferencias entre la situación de mediados del siglo XX y la de hoy. El acceso a la parcela se consideraba anteriormente como un privilegio que permitía al heredero del padre ejidatario asentarse en el pueblo 
y beneficiarse de cierta estabilidad transmitida por la tierra, mientras que los otros hermanos y hermanas tenían que "buscarse la vida". Hoy en día la producción de una parcela se considera más bien un complemento a otras actividades, que no está valorado en todos los casos porque implica muchas responsabilidades.

\section{Las consecuencias territoriales y sociales de la pluriactividad en Chavarrillo}

En el caso de Chavarrillo la pluriactividad es claramente una estrategia para diversificar los ingresos y mantener la finca. Si existe un equilibrio en ciertos casos entre los beneficios de las actividades agrícolas y no agrícolas, se ha vuelto muy difícil vivir solamente del campo pero continúa siendo una actividad económica y simbólicamente importante para gran parte de la población, la cual sigue teniendo acceso a la tierra. Esto se explica porque el cultivo del limón todavía es rentable, sobre todo desde que se empezó a exportar, por el gusto que le tienen a la actividad, y también porque es una manera de apoyar a los hermanos que no estudiaron. El contador Sergio contó, por ejemplo, que a pesar de que "el campo le ayuda rara vez, él es el que ayuda al campo", y considera importante seguir con el cultivo del limón y del café. Cuando no se trata de un trabajo asalariado, sino de un negocio propio, los productores consideran que la doble actividad permite el mantenimiento de cierto equilibrio en los ingresos. Finalmente, el apego a la tierra de los antepasados, el hecho de no querer dejar el legado de un padre que luchó por mantener su parcela, el considerarse campesinos a pesar de tener doble actividad y la herencia aún fuerte de la historia agrarista, constituyen sin duda elementos claves para entender la importancia que tiene todavía el campesinado en el pueblo.

La multiplicación de las otras actividades ha tenido, sin embargo, varias consecuencias. La primera es la poca presión que existe sobre la tierra. Las zonas más lejanas e inaccesibles del ejido fueron abandonadas o semiabandonadas desde hace aproximadamente dos décadas. La barranca, ideal para el cultivo del café, por ejemplo, no convenía tanto para los limonares.
Además, es accesible solamente por senderos y las cosechas se pueden transportar únicamente a hombro o con bestias. Por la misma falta de presión, no se han hecho inversiones en infraestructuras para acceder con vehículos a estas tierras. Los cafetales fueron poco a poco ganados por la vegetación natural — acahuales-, y sólo algunos campesinos los siguieron cosechando, pero sin invertir en ellos (ver foto 1). En 2014, la caída de unos árboles después de una tormenta dificultó aún más el acceso a las fincas y la roya afectó fuertemente a los cafetales, lo que provocó que los campesinos renunciaran totalmente a ir a este lugar. Los mangos, cultivo principal en una parte de la barranca, dejaron también de producir. ${ }^{13}$ En la actualidad son muy pocos los campesinos que siguen chapeando su parcela o van a cosechar un poco de café y los plátanos roatán. La vegetación ha ganado en densidad y en diversidad, pero es un fenómeno poco significativo, ya que los cafetales convivían con la cobertura forestal y sin uso de agroquímicos. El cerro, de suelos calizos, que fue plantado de cafetales solamente en su parte baja - hondonada - no conviene tampoco para el cultivo del limón, por lo cual sigue cubierto por un bosque de encinos, huizaches, higueras, palos mulatos, etcétera. La loma se dejó de cultivar en gran parte también por la pérdida de fertilidad de los suelos. Las tierras de los alrededores del río y del pueblo, las más accesibles y adecuadas para los limonares, son las que se cultivan en la actualidad de manera intensiva, con un uso casi homogéneo para las huertas.

Otro cambio importante se debe a la lotificación en el año 2009 de 56 hectáreas de tierra común del ejido, en la fracción del ejido llamada "el llano", y a la venta de parte de estos lotes para la construcción de viviendas. Esta fracción, cercana a la autopista Xalapa-Veracruz, a un lado del aeropuerto de Xalapa, corresponde a una de las zonas de expansión más fuerte de la ciudad en los últimos años y resulta muy atractiva para las constructoras e inversores. Aunque no se ha construido aún por la ausencia de servicios, podría volverse un fraccionamiento formal y consolidado en los próximos años. Es interesante ver cómo a nivel geográfico se van polarizando las actividades y las construcciones a lo 
largo de este eje de comunicación y rumbo a la ciudad, en detrimento de otras zonas antaño atractivas y productivas, que caen en el abandono, como es el caso de la barranca.

Las relaciones de Chavarrillo con Xalapa, que se han vuelto cada vez más estrechas con el desarrollo de la pluriactividad, la multiplicación de los movimientos pendulares y la presencia de una ruralidad sin agricultura en especial con los jóvenes, podrían incrementarse más todavía con la extensión del proceso de urbanización de la capital hacia esta antigua parte del ejido.

\section{Tlalnelhuayocan: permanencia de la milpa y diversificación de actividades no campesinas}

En el caso de Tlalnelhuayocan, es difícil calcular - aun aproximadamente- cuál es la relación entre las Unidades Familiares Rurales y las Unidades Económicas Campesinas Pluriactivas porque los ejidatarios viven en distintas localidades del municipio - Tlalnelhuayocan, Rancho Viejo, Mesa Chica, Otilpan-y las pequeñas propiedades, aunque reducidas en tamaño, son numerosas. A partir de las entrevistas realizadas, evaluamos que las Unidades Familiares Rurales, sin acceso a la tierra, son las más numerosas, por lo cual se van a tratar en primer lugar.

\section{Las Unidades Familiares Rurales: actividades en Xalapa}

En la actualidad muchas de las familias de la localidad no tienen fincas, lo que sin duda tiene como origen el hecho de que el reparto agrario de 1925 no pudo satisfacer las necesidades en tierras de la mayor parte de la población. Posteriormente, la fragmentación de las parcelas limitó aún más el acceso a la tierra. Otras familias poseen terreno, pero no tienen contacto directo con las actividades agrícolas. Desde hace tres décadas, gran parte de los hombres se emplea en la industria de la construcción en Xalapa, lo que coincide justamente con el periodo de mayor auge del crecimiento de esta ciudad y de demanda de mano de obra para la construcción de inmuebles. Algunos de estos antiguos campesinos se han consolidado económicamente como maestros albañiles, como es el caso del actual presidente del Comisariado Ejidal de San Andrés, quien vivió del trabajo agrícola hasta los 30 años, hasta que esta actividad dejó de ser rentable y decidió incursionar en la albañilería (entrevista a EHC, Tlalnelhuayocan, 8 de agosto de 2015). Actualmente un maestro de albañilería gana trescientos pesos diarios, aunque la mayoría de los trabajadores se emplean como ayudantes de pintor o de albañil. Este es un trabajo inestable ya que depende de la demanda; el día de trabajo se paga entre 100 y 150 pesos, de los cuales hay que descontar el precio del pasaje de ida y vuelta a Xalapa - 36 pesos - y la comida. Cuando no se presenta ninguna oportunidad en la ciudad, los trabajadores eventuales de la construcción intentan emplearse como peones en el campo, aunque la demanda de trabajo en este rubro se circunscribe a ciertas fases del cultivo del maíz — siembra y cosecha principalmente-

En la última década se han multiplicado las opciones de trabajar como taxistas, y en menor medida como choferes de autobuses urbanos. Los taxistas trabajan con un patrón, residente de Xalapa, que les alquila su vehículo una parte del día a cambio del pago de una cuota de 300 pesos por 12 horas aproximadamente. Descontando esta cuota y el gasto en gasolina, los trabajadores calculan que ganan en promedio 150 pesos al día. Este trabajo representa más estabilidad y menos esfuerzo físico que el anterior, y el requisito es mínimo: tener una licencia de manejo de la Dirección General de Tránsito.

Además de estas actividades, en Tlalnelhuayocan un número considerable de mujeres - jóvenes y adultas - se dedica a la elaboración de productos de maíz — tortillas, gorditas, tlacoyos - para su comercialización. Esta actividad permite completar los ingresos obtenidos por los hombres e incluso sustituir al trabajo masculino cuando éste escasea. Las señoras compran el maíz en bultos en las tiendas de abarrotes del pueblo, y después de nixtamalizarlo lo llevan al molino más cercano. Ellas mismas elaboran las tortillas en un fogón de leña y las colocan en paquetes de doce a quince tortillas que venden al precio de entre ocho y doce pesos en los tianguis, mercados y calles de 
Xalapa y Coatepec. Esta actividad puede ser diaria o de algunos días a la semana según las necesidades y la demanda. María del Rosario, por ejemplo, se organiza con sus dos concuñadas para elaborar las tortillas en la mañana, un día de cada dos. Al medio día, una de ellas sale en transporte urbano con cuarenta paquetes de trece unidades para vender a diez pesos el paquete en una calle de Coatepec. Si se resta el precio de los insumos - bulto de maíz, gasto de molino, leña, transporte a Coatepec-, calcula que pueden ganar semanalmente entre quinientos y seiscientos pesos. Las tres mujeres comparten las ganancias, que sirven de complemento a las de sus esposos, los tres taxistas en Xalapa (entrevista a MRGB, Tlalnelhuayocan, 14 de agosto de 2015).

Relacionada con esta actividad, la extracción de leña se sigue dando por la necesidad que implica la manufactura — nixtamalización y cocción - de las tortillas. Al quedar pocas superficies arboladas disponibles, se recolecta leña seca en parcelas de cultivo, ya sean propias o ajenas, en tanto que algunos hombres trabajan como leñadores de tiempo completo, cortando árboles por la zona de Otilpan, Rancho Viejo y San Antonio, al sur de la cabecera municipal, donde todavía hay monte alto. Estos leñadores compran a los propietarios de parcelas árboles para convertirlos en leña y, al decir de los entrevistados, actualmente en el ejido se llevan a cabo prácticas de reforestación pues saben que una fuente importante de los ingresos familiares - la elaboración de tortillas para su ventadepende de la existencia de árboles. La carga de leña de ochenta kilos se vende a ciento cincuenta pesos y ésta, por lo general, dura de dos a tres días en los hogares, en los que las mujeres hacen tortillas para vender.

\section{Unidades Económicas Campesinas Pluriactivas: el predominio de los cultivos de subsistencia}

En Tlalnelhuayocan, las superficies cultivadas son en general muy reducidas; los campesinos - ejidatarios, pequeños propietarios y arrendatarios - laboran superficies de dos o tres hectáreas máximo, ${ }^{14}$ y casi no hay cultivos comerciales, al contrario de lo que pasa en
Chavarrillo con el limón y el café. Por las condiciones naturales y el tamaño reducido de las parcelas, se siguen sembrando en la actualidad sobre todo cultivos de subsistencia, por lo cual no se puede considerar el campo como una fuente importante de ingresos, sino más bien sirve de complemento a las actividades descritas en el apartado anterior.

Los habitantes de la localidad saben que el trabajo en la ciudad es incierto, además de que los sueldos son bajos y generalmente no tienen prestaciones sociales, por lo que, aunque para muchos el trabajo no agrícola es su principal fuente de ingresos, no abandonan por completo la agricultura, pues están conscientes de que contar con su propia cosecha de maíz representa una posibilidad valiosa de reducir los gastos del hogar. El señor Tiburcio, un ayudante de albañil que trabaja de manera temporal, siembra maíz para autoconsumo en una parte del cuarto de hectárea de parcela ejidal que heredó de su madre. Obtiene solamente doscientos kilos por año, ya que no invierte en la aplicación de agroquímicos - fertilizantes, herbicidas, plaguicidas - , pero es una manera para él de aliviar la economía familiar, pues durante algunos meses las tortillas se elaboran en el hogar para sus tres miembros y no hay necesidad de comprarlas (entrevista a TBH, Tlalnelhuayocan, 11 de agosto de 2015). Vale la pena incluso rentar un pedazo de terreno, como lo hace don Tranquilino, de la localidad de Otilpan, quien alquila un cuarto de hectárea cada año a propietarios distintos para sembrar maíz y frijol, cuya cosecha es únicamente para el consumo de su familia (entrevista a TMG, Otilpan, 14 de agosto de 2015).

Otro caso es el de don Constantino, carnicero, que posee dos pequeñas propiedades de una hectárea cada una; la primera la compró con el dinero de su oficio y la segunda la heredó de su padre. Cultiva maíz y un poco de frijol en ambas, y las utiliza también como potrero para sus vacas. El cultivo es sólo para el autoconsumo: obtiene mil kilos de maíz, lo que le permite evitar su compra para la elaboración de las tortillas del hogar -doce personas-durante ocho meses aproximadamente (entrevista a CRD, Tlalnelhuayocan, 14 de agosto de 2015)..$^{15}$ Las otras 
actividades de don Constantino son comerciales: vende la leche de sus vacas por litro a habitantes del pueblo y mata puercos que compra para despachar la carne en su misma casa.

Para las familias campesinas que siguen teniendo el campo como actividad principal, la diversificación de las actividades parece ser la única manera de acceder a cierta estabilidad económica. El cultivo de hortalizas, como el rábano, la acelga, la lechuga, el cilantro o la espinaca, se ha extendido debido a que estos productos son de ciclo corto - se siembran en la temporada de invierno - y bastante rentables. También se cultiva maíz elotero, el cual se siembra en febrero y se cosecha dos o tres meses después; una hectárea de maíz elotero produce alrededor de 15000 elotes y cada pieza se vende a 1.50 pesos en la Central de Abastos de Xalapa. Don Eulodio, ejidatario que posee 1.75 hectáreas, cultiva en su milpa maíz de grano y elotero, frijol y calabazas. Además, siembra hortalizas para su comercialización en un pedazo cercano a su casa, de septiembre a mayo, después de la cosecha del maíz (ver foto 2). Otra parte de la parcela le sirve como potrero para sus dos vacas lecheras, y tiene también marranas criadoras para venta de lechones. Gracias a la combinación de estas distintas actividades, a la venta en el mercado San José de Xalapa de las calabazas y sus flores, de las hortalizas y de los elotes, y a pesar del tamaño modesto de su parcela, don Eulodio ha podido comprar sucesivamente, desde el año 1995, tres tiendas de abarrotes en diferentes puntos del pueblo, en las cuales trabajan sus hijas (entrevista a ELH, Tlalnelhuayocan, ll de agosto de 2015).

Lo que acabamos de describir son las opciones de cultivos comerciales a las que tienen acceso los campesinos. Desde hace alrededor de veinte años se introdujo otro tipo de cultivos comerciales - aguacate Hass y nuez de macadamia-, pero éstos sólo están al alcance de propietarios privados ya que requieren altos costos de producción; además, se ubican fuera del polígono San Andrés del ejido Tlalnelhuayocan (Gerez et al., 2012: 158)

Para complementar los ingresos, se practica también la renta de tierras: don Constantino, por ejemplo, después de su cosecha de maíz, da una hectárea en renta a un señor que la utiliza para la siembra de papas. Es importante señalar que, en la totalidad del municipio, la renta de tierras por un ciclo, por parte de paperos originarios del municipio vecino de Acajete — situado al noroeste- ha aumentado en los últimos años. El precio de la renta es variable, según el tipo de tierra y la zona, pero en general es alto: Alfonso V. renta por ejemplo una media hectárea en 4000 pesos por un ciclo de siembra de cuatro meses y medio (entrevista JLVH, hijo de Alfonso, 8 de diciembre de 2015).

Si en el caso de Tlalnelhuayocan también tener acceso a la tierra sigue siendo importante, las razones son distintas de las que evocan los pobladores de Chavarrillo, ya que para aquéllos cultivar maíz durante un ciclo en un pedazo de tierra, sea rentado o propio, permite evitar la compra de un producto alimenticio básico. Se considera como un ahorro que se hace sobre las ganancias provenientes de los salarios. Se trata entonces de una respuesta a una situación económica: la importancia que se da a este pedazo de tierra cultivado y el esfuerzo que se invierte ilustran la escasez general de los ingresos. Sólo los que diversifican la milpa con otros cultivos venden los sobrantes de sus cosechas, siempre en pequeñas cantidades. Para las jóvenes generaciones, la única perspectiva es heredar un pedazo de tierra muy fragmentado, en la que no puede practicar cultivos rentables, por lo cual se inclinan masivamente hacia los empleos urbanos, aunque precarios y mal pagados.

\section{La evolución de las actividades de Tlalnelhuayocan}

Para las familias campesinas de Tlalnelhuayocan ha sido una constante la necesidad de completar sus ingresos con otras actividades, esencialmente comerciales, lo cual han podido hacer gracias a la cercanía con Xalapa - lugar al que en las décadas de de 1950 y 1960 llegaban a pie - para vender sus excedentes de cosechas, leche, leña y madera, así como algunos productos artesanales y de recolección - hierbas, flores - Otra fuente importante de ingresos fue el empleo estacional para el corte de café en las fincas ubicadas al sur del municipio de Xalapa.

Don Eulodio, por ejemplo, rememora que hasta en los años setenta y ochenta llegaban camiones de toda 
la región cafetera del sur de Xalapa —-Las Ánimas, Las Trancas, Coatepec, Chavarrillo- al pueblo a recoger trabajadores para el corte del café. Don Agustín, a su vez, recuerda que él y su familia se trasladaron a vivir a Zoncuantla, en el municipio de Coatepec, para emplearse en el corte de café, en tanto que él consiguió trabajo en el mismo lugar como encargado de un pequeño rancho ganadero. Después trabajó cerca de veinte años con una familia que poseía ochenta hectáreas de fincas de café en Zoncuantla (entrevista AHD, 4 de diciembre de 2015). Es decir, hasta la década de 1970, para los hombres de Tlalnelhuayocan la opción principal de trabajo asalariado era el corte del café. Sin embargo, la caída del precio internacional de este grano redujo considerablemente el mercado de trabajo.

Al mismo tiempo, la pérdida de rentabilidad de las actividades del campo a nivel nacional y la sustitución de la leña por el gas en numerosos hogares y labores artesanales de Xalapa afectaron las producciones agropecuarias y forestales (Fernández, 2010). Los hombres abandonaron progresivamente las ventas de cargas de leña, de madera, y la elaboración de artesanía, para dedicarse a la construcción, los negocios y los empleos independientes.

En cuanto al trabajo femenino, éste ha sido una constante en Tlalnelhuayocan para complementar los ingresos familiares o para mantener a los hijos e hijas en casos de viudez o abandono de esposos, empleándose en el servicio doméstico en casas de Xalapa o vendiendo productos en la ciudad. Anteriormente, las ventas eran de pequeñas cantidades de algunas producciones obtenidas en el campo - hierbas medicinales y condimentos, hortalizas, flores-, y las mujeres acudían también a los mercados y tianguis de Xalapa para comprar verduras y hortalizas a primera hora y revenderlas en las afueras o en las calles, con lo que obtenían una ganancia mínima. Un ejemplo es el de la madre del señor Agustín, que quedó viuda a mediados de la década de 1940 con cinco hijos que mantener, así que empezó a ir a una localidad -Mesa de La Yerba- del vecino municipio de Acajete, a comprar flores que ahí se producían. El sábado a temprana hora salía caminando, acompañada de un hijo pequeño, a
Mesa de La Yerba, en donde adquiría diversos tipos de flores - alcatraces, azucenas y otras - que al día siguiente llevaban a vender a Xalapa. A esta ciudad se trasladaban a pie, comenzando a ofrecer sus flores desde que entraban a la ciudad hasta que llegaban a su destino: el mercado de San José, en donde se ubicaban en una banqueta con su mercancía en venta (entrevista AHD, 4 de diciembre de 2015).

La competencia de verduras y flores procedentes de Puebla, y la demanda de tortillas y gorditas hechas a mano, en expansión en los últimos veinte años tanto en Xalapa como en Coatepec, han provocado un giro en las actividades comerciales femeninas de Tlalnelhuayocan. La ventaja de las tortillas es que ahora gran parte del trabajo se hace en casa y no hay necesidad de que todas salgan a vender, como se ha visto en el caso de María del Rosario y sus concuñadas. Sin embargo, es una labor que afecta la salud de las mujeres, quienes se quejan de dolor de hombros y saben que la inhalación de humo es perjudicial. Por otra parte, algunas mujeres mantienen la práctica de emplearse en el trabajo doméstico en Xalapa, y los hombres y mujeres jóvenes escolarizados se han incorporado también al empleo en comercios de esta ciudad.

\section{Cambios sociales y territoriales moderados}

En el caso de Tlalnelhuayocan, la pluriactividad con sus múltiples facetas representa desde hace varias décadas un intento por salir de la pobreza, y la ruralidad sin agricultura no es un evento reciente. Si las idas y vueltas diarias a Xalapa se han multiplicado y los vínculos comerciales se han reforzado en las últimas décadas, no parece sin embargo que éstas hayan aportado grandes mejoras a las condiciones de vida de los habitantes de la localidad, que sigue clasificada con un índice de marginación alto (Acosta, 2011).

Existe cierta estabilidad en cuanto a la superficie de las tierras cultivadas en la localidad, esto por dos razones: hay poca presión por ampliar las áreas de cultivos debido a que en las últimas décadas un número creciente de sus habitantes se ha incorporado al mercado laboral urbano. Pero, por otra parte, tampoco existe un 
fenómeno de abandono del campo, ya que las personas de bajos recursos que no tienen acceso a la tierra rentan pequeñas superficies de manera temporal para sembrar maíz. Las tierras rentadas pueden ser de personas que, como el actual presidente del Comisariado Ejidal, obtienen un recurso suficiente de su trabajo en Xalapa y rentan su parcela ejidal porque no tienen tiempo para dedicarse a la agricultura.

Las superficies boscosas se han estabilizado también porque, si bien todavía hay demanda de leña a nivel del pueblo, ésta ha disminuido mucho en Xalapa como consecuencia del uso del gas y de otros materiales de construcción. Por otra parte, en la conservación del bosque interviene también el hecho de que las tierras boscosas de Tlalnelhuayocan están incorporadas al programa de Servicios Ambientales de la Comisión Nacional Forestal (CONAFOR), que otorga mil pesos por hectárea conservada. Si en el pasado la frontera agrícola avanzó en detrimento de los bosques, en la actualidad se puede considerar que la situación se ha estabilizado.

En cuanto a la expansión urbana, ésta es más visible en el sur del municipio, particularmente en localidades como Rancho Viejo, y en la periferia de la ciudad de Xalapa, ya que en los años ochenta se lotificó una parte del ejido para construir la colonia Guadalupe Victoria, que ha pasado a formar parte de la mancha urbana. La expansión urbana se observa también en la cercanía de la cabecera municipal: en este caso, son casas aisladas situadas en grandes terrenos al norte del pueblo, construidas por personas de ingresos altos que van y vienen a Xalapa, donde trabajan. Estos habitantes de origen urbano eligieron Tlalnelhuayocan para construir sus residencias por los precios todavía accesibles de los terrenos y por la tranquilidad y el paisaje arbolado, por lo cual se ha conservado en gran parte la vegetación natural.

\section{Conclusiones}

Los pueblos de Chavarrillo y Tlalnelhuayocan, a pesar de pertenecer ambos a la periferia de Xalapa y de tener una pluriactividad alta, presentan situaciones muy contrastadas. En Chavarrillo, la actividad agrícola sigue generando ingresos económicos debido a los cultivos comerciales que ahí se pueden practicar, lo cual explica el que muchos ejidatarios y posesionarios que tienen actividades no campesinas decidan mantener su parcela en producción. A pesar de tener acceso a empleos urbanos estables y relativamente bien remunerados, se niegan a separarse de la herencia de sus padres. Existe una identidad local fuerte y un arraigo a las tierras de los abuelos y padres, así como una dinámica comunitaria que persiste incluso en las generaciones más jóvenes. Pese a esto, y en respuesta a la pregunta que nos planteamos al inicio, sí ha habido un proceso moderado de abandono de las actividades agrícolas. En parte, este proceso se ha debido a las políticas estatales de restringir al mínimo, o incluso anular, los apoyos financieros y técnicos a la producción agrícola. Así, la intensificación y expansión de la pluriactividad ha permitido mantener la parcela, pero al mismo tiempo ha estado acompañada por una reducción de la diversidad productiva, de tal forma que actualmente en Chavarrillo se depende prácticamente de un solo cultivo comercial, lo que necesariamente vulnera sus condiciones de producción.

En Tlalnelhuayocan, las características naturales, el difícil acceso a la tierra y la fragmentación de las parcelas, sean de propiedad privada o ejido, han dificultado siempre la rentabilidad de la actividad campesina, que resulta ser hoy en día sólo una respuesta económica, un "ahorro" y complemento a otras actividades, comerciales y urbanas. La cercanía de Xalapa y las estrategias de diversificación de las actividades parecen haber sido insuficientes, en este caso, para mejorar las condiciones de vida de la mayoría de la población. Sin embargo, aquí también ha sido moderado el proceso de abandono de la actividad agrícola, aunque por causas diferentes a las de Chavarrillo. La preservación de la agricultura no se debe a la existencia de algún cultivo comercial rentable, aunque como mencionamos se busca mejorar los ingresos provenientes del cultivo del maíz sembrando maíz elotero y hortalizas. El motivo principal por el que se mantiene la actividad agrícola es porque los trabajos urbanos a los que tiene acceso esta población de origen indígena son inestables y de bajos salarios: conservar las 
parcelas, ya sea para siembras de autoconsumo o para renta de las mismas, ha sido la regla.

En suma, como bien ha señalado Schneider (2009: 209), el análisis de la pluriactividad, en tanto elemento constitutivo de la nueva ruralidad, debe considerarse siempre en relación con "un determinado contexto social y económico". Los casos que hemos presentado aquí muestran que, si bien la pluriactividad es una constante en la organización económica actual de las familias campesinas de Chavarrillo y Tlalnelhuayocan, ésta tiene distintas motivaciones y consecuencias derivadas de la superficie de tierra a la que se tiene acceso, del tipo de suelo de las parcelas, de la ubicación de los poblados en relación con las principales vías de comunicación y del origen étnico de los campesinos, entre otros aspectos.

Por otra parte, a pesar de lo contrastante de las condiciones de producción agrícola entre ambos lugares, también existen situaciones compartidas entre las que destacan la creciente importancia del trabajo urbano en Xalapa, a la par que la mayoría de los trabajadores de los dos lugares mantiene su residencia en sus lugares de origen, a los que regresan cada día al final de su jornada laboral ya que ésta resulta una mejor opción que trasladarse a vivir a la ciudad, por razones económicas pero también, sin duda, culturales. El crecimiento de esta población rural con ingresos provenientes de actividades asalariadas urbanas y con vínculos muy estrechos con la urbe implica cambios en los modos de vida de las localidades, por ejemplo, en los hábitos de consumo, el acceso a las nuevas tecnologías, la búsqueda de adquisición de los mismos bienes y las actividades de ocio, entre otros. Esto está provocando cierta homogeneización en los patrones de conducta de la población en contraste con otros rasgos diferenciadores entre ambos lugares, como la fuerte identidad agrarista de Chavarrillo, frente a una tradición de pequeña propiedad agraria que en Tlalnelhuayocan coexiste con la propiedad ejidal. Si en Chavarrillo todavía se rinden honores públicos al líder agrarista local, en Tlalnelhuayocan la propiedad de la tierra no tiene como origen único el ejido posrevolucionario.

\section{Notas}

${ }^{1}$ Ver, entre otros, los trabajos de Carton de Grammont (2001 y 2009a), Rubio (2004 y 2006), Arias (2005) y Appendini y Torres-Mazuera (2008).

${ }^{2}$ Con una población de 666535 habitantes y una superficie de 867 kilómetros cuadrados (INEGI, 2010).

${ }^{3}$ Esta hacienda, que perteneció una temporada a Santa Anna, se formó mediante el otorgamiento de mercedes en el siglo XVI y fue creciendo hasta el siglo XIX (Sánchez, 1979).

${ }^{4}$ Dotación provisional en 1931, Resolución Presidencial en 1934, fecha de ejecución en 1935 (AGEV, CAM, exp. 168; PHINA).

5 La localidad cambió el nombre de San Andrés Tlalnelhuayocan por el de Tlalnelhuayocan, mismo nombre del municipio, en 1932 (INEGI, Archivo Histórico de Localidades). Sin embargo, en la práctica se sigue utilizando comúnmente el nombre de San Andrés para referirse a la cabecera municipal.

${ }^{6}$ La primera solicitud ejidal por parte de los vecinos del pueblo data del año 1918. La dotación definitiva se concedió en 1935 con 1024 hectáreas (AGEV, CAM, exp. 93).

${ }^{7}$ Llamamos finca a una unidad de producción agrícola, la cual puede estar constituida por una o más parcelas.

${ }^{8}$ De acuerdo con el Sistema Padrón e Historial de Núcleos Agrarios (PHINA), en Chavarrillo hay 76 ejidatarios y 198 posesionarios; estos datos fueron corroborados por los ejidatarios entrevistados

${ }^{9}$ En la primera empresa los horarios son de 8:00h a 20:00h con una hora de receso para la comida y descanso dominical. En la segunda, los horarios son de 8:00h a 17:00h, con horas extras durante la temporada alta y descanso dominical.

${ }^{10}$ La cercanía de Xalapa implica ciertas facilidades para acceder a la Universidad Veracruzana y otras escuelas.

${ }^{11}$ Media hora en coche, aunque se pueda duplicar el tiempo de recorrido en ciertos horarios.

${ }^{12}$ Se construyeron túneles para que la vía pase debajo del cerro cuando antes lo rodeaba.

${ }^{13}$ La floración de los mangos ha sido limitada en los últimos años por las temperaturas altas. Por otra parte, 
se ha desarrollado una plaga de gusanos que no deja obtener producción aun cuando se da la floración.

${ }^{14}$ Según el PHINA, secensaron 161 ejidatarios y comuneros después del PROCEDE (Programa de Certificación de Derechos Ejidales y Titulación de Solares). Parte de ellos viven en Rancho Viejo, cerca del polígono 2 del ejido, y no en Tlalnelhuayocan.

${ }^{15}$ Don Constantino es viudo, vive con tres de sus hijos, las esposas de éstos y cinco nietos.

\section{Referencias bibliográficas}

Acosta-García, Sara (2011). "Migración y pobreza: la formación de economías domésticas en archipiélago en el municipio de Tlalnelhuayocan, Veracruz". Tesis de licenciatura en Geografía. Universidad Veracruzana, Facultad de Economía. Xalapa.

Appendini, Karen y Gabriela Torres-Mazuera (eds.) (2008). ¿Ruralidad sin agricultura? Perspectivas multidisciplinarias de una realidad fragmentada. México: El Colegio de México.

Arias, Patricia (2005). "Nueva ruralidad: antropólogos y geógrafos frente al campo hoy". En Héctor ÁvilaSánchez (coord.), Lo urbano-rural. iNuevas expresiones territoriales? México: Universidad Nacional Autónoma de México-Centro Regional de Investigaciones Multidisciplinarias, pp. 123-159.

Arias, Patricia (2009a). Del arraigo a la diáspora. Dilemas de la familia rural. México: H. Cámara de Diputados LX Legislatura/Universidad de Guadalajara/Miguel Ángel Porrúa.

Arias, Patricia (2009b). "La pluriactividad rural a debate". En Hubert C. de Grammont y Luciano Martínez Valle (coords.), La pluriactividad en el campo latinoamericano. Ecuador: FLACSO-Sede Ecuador, pp.171-206.

Barkin, David (2013). "La construcción del nuevo mundo del campesinado mexicano”. En Tanalís Padilla (coord.) El campesinado y su persistencia en la actualidad mexicana. México: Fondo de Cultura Económica/Consejo Nacional para la Cultura y las Artes, pp. 469-500.

Carton de Grammont, Hubert (2001). "El campo mexicano a finales del siglo XX". En Revista Mexicana de Sociología, 63(4): 81-108.
Carton de Grammont, Hubert (2009a). "La desagrarización del campo mexicano". En Convergencia. Revista de Ciencias Sociales, 16(50): 13-50.

Carton de Grammont, Hubert (2009b). "La nueva estructura ocupacional en los hogares rurales mexicanos". En Hubert C. de Grammont y Luciano Martínez Valle (coords.), La pluriactividad en el campo latinoamericano. Ecuador: FLACSO-Sede Ecuador, pp. 273-307.

Casas-Mendoza, Carlos Alberto (1993). "Familia y poder. La identidad de una comunidad del centro de Veracruz". Tesis de licenciatura. Universidad Veracruzana, Facultad de Antropología. Xalapa.

CONAPO (Consejo Nacional de Población) (2010). "Delimitación de las zonas metropolitanas de México 2010". México. Disponible en: http://www.conapo. gob.mx/es/CONAPO/Zonas_metropolitanas_2010 (consultado el 13 de agosto de 2015).

Espinoza-Ortega, Angélica, Adolfo Álvarez-Macías, María del Carmen del Valle y Michelle Chauvet (2005). "La economía de los sistemas campesinos de producción de leche en el Estado de México". En Técnica Pecuaria en México, 43(1). Mérida: INIFAP. Disponible en: http://www.redalyc.org/articulo. oa?id=61343104 (consultado el 14 de septiembre de 2016).

Fernández-Cabrera, Leticia (2010). “Análisis de los factores socioeconómicos que influyen en el cambio de uso de suelo en la localidad de Otilpan, Tlalnelhuayocan, 1980 a 2009". Tesis de licenciatura en Geografía. Universidad Veracruzana, Facultad de Economía. Xalapa.

Florescano-Mayet, Sergio (1992). "Xalapa y su región durante el siglo XIX: las principales vertientes de su desarrollo económico, social y político". En La Palabra yel Hombre, 83: 135-166.

Gerez, Patricia et al. (2012). "Características sociales y problemática de la subcuenca". En Luisa Paré y Patricia Gerez (coords.), Al filo del agua: cogestión de la subcuenca del río Pixquiac, Veracruz. México: UNAM/Sendas, A.C./Universidad Veracruzana/ SEMARNAT/INE/UIA, Campus Puebla/Juan Pablos Editor, pp. 135-190. 
Hecht, Susanna B. et al. (2006). "Globalization, Forest Resurgence and Environnmental Politics in El Salvador". En World Development, 34(2): 308-323.

INEGI (Instituto Nacional de Estadística y Geografía) (s.f.). "Archivo Histórico de Localidades". México. Disponible en: http://www.inegi.org.mx/geo/ contenidos/geoestadistica/consulta_localidades.aspx (consultado el 26 de junio de 2015).

INEGI (Instituto Nacional de Estadística y Geografía) (2010). "Delimitación de las zonas metropolitanas de México, 2010". Disponible en: http://www3.inegi.org. $\mathrm{mx} /$ sistemas/biblioteca/ficha.aspx?upc $=702825003884$ (consultado el 13de agosto de 2015).

Kay, Cristóbal (2009). "Estudios rurales en América Latina en el periodo de globalización neoliberal: iuna nueva ruralidad?". En Revista Mexicana de Sociología, 71(4): 607-645.

Kay, Cristóbal (2016). "La transformación neoliberal del mundo rural: procesos de concentración de la tierra y del capital y la intensificación de la precariedad del trabajo". En Revista Latinoamericana de Estudios Rurales, I(1): 1-26. Disponible en: http://www.ceil-conicet. gov.ar/ojs/index.php/revistaalasru/article/view/93 (consultado el 12 de septiembre de 2016).

Lara-Flores, Sara María (coord.), (2010) Migraciones de trabajo y movilidad territorial. México, H. Cámara de Diputados, LXI Legislatura/CONACYT/Miguel Ángel Porrúa.

Lara-Flores, Sara María (1998). Nuevas experiencias productivas y nuevas formas de organización flexible del trabajo en la agricultura mexicana. México: Juan Pablos Editores/Procuraduría Agraria.

León-Fuentes, Nelly (2009). Los debates y las batallas por el agua en Xalapa 1838-1882. Xalapa: Universidad Veracruzana-Instituto de Investigaciones HistóricoSociales.

Marchal, Jean-Yves y Rafael Palma G. (1985). Análisis gráfico de un espacio regional, Veracruz. Xalapa: Laboratorio de Investigación y Desarrollo RegionalINIREB/ORSTOM.

Martínez-Borrego, Estela y Janett Vallejo-Román (2011). "Las nuevas relaciones rural-urbanas y mercados de trabajo en Morelos y el Estado de México". En Hernán J. Salas-Quintanal, María Leticia Rivermar-Pérez y Paola VelascoSantos (eds.), Nuevas ruralidades. Expresiones de la transformación social en México. México: UNAMInstituto de Investigaciones Antropológicas/Juan Pablos Editor, pp. 29-57.

Martínez-Valle, Luciano (2009). "La pluriactividad entre los pequeños productores rurales: el caso ecuatoriano". En Hubert C. de Grammont y Luciano Martínez Valle (coords.), La pluriactividad en el campo latinoamericano. Ecuador: FLACSO-Sede Ecuador, pp. 81-102.

Méndez-Sastoque, Marlon Javier (2009). "Incursión ocupacional rural en escenarios no agrícolas y urbanos: tendencias y desafíos". En Hubert C. de Grammont y Luciano Martínez Valle (coords.), La pluriactividad en el campo latinoamericano. Ecuador: FLACSO-Sede Ecuador, pp. 127-144.

Mestries Benquet, Francis (2003). "Crisis cafetalera y migración internacional en Veracruz”. En Migraciones Internacionales, 2(2): 121-148.

PHINA (Padrón e Historial de Núcleos Agrarios). Disponible en: http://phina.ran.gob.mx/phina2 (consultado el 12 de mayo de 2015).

Rosas, Mara y Mario Fuente (2013). "La Nueva Ruralidad Comunitaria y las actividades no-proletarias generadoras de excedentes". En Tanalís Padilla (coord.), El campesinado y su persistencia en la actualidad mexicana. México: Fondo de Cultura Económica/Consejo Nacional para la Cultura y las Artes, pp. 428-468.

Rubio, Blanca (2004). "El sector agropecuario mexicano en los años noventa: subordinación desestructurante y nueva fase productiva". En Blanca Rubio (coord.), El sector agropecuario mexicano frente al nuevo milenio. México: UNAM/Plaza y Valdés Editores, pp. 17-45.

Rubio, Blanca (2006). "Balance rural del sexenio de Vicente Fox Quezada. La ruta de la continuidad, 2001-2006". En Rumbo Rural, 2(5): 40-51.

Salas-Quintanal, Hernán y María Leticia Rivermar-Pérez (2011). "Nuevas ruralidades en el sur de Tlaxcala". En Hernán J. Salas-Quintanal, María Leticia RivermarPérez y Paola Velasco-Santos (eds.), Nuevas ruralidades. Expresiones de la transformación social en México. México: 
UNAM-Instituto de Investigaciones Antropológicas/ Juan Pablos Editor, pp. 139-163.

Sánchez-Gómez, Rosa Catalina (1979). "Afectación agraria y población beneficiada en la hacienda El Encero”. En Anuario II. Xalapa: Universidad Veracruzana, pp. 160-182.

Schneider, Sergio (2009). "La pluriactividad en el medio rural brasileño: características y perspectivas para la investigación". En Hubert C. de Grammont y Luciano Martínez Valle (coords.), La pluriactividad en el campo latinoamericano. Ecuador: FLACSO-Sede Ecuador, pp. 207-242.

Thiébaut, Virginie (2012). "La transformation des paysages agraires mexicains. Cultures de la canne à sucre et de la mûre dans la vallée de Los Reyes, Michoacán". En Cybergeo: European Journal of Geography. Environnement, Nature, Paysage, article 626. Disponible en : http://cybergeo.revues. org/25657 (consultado el 10 de septiembre de 2016).
Velázquez H., Emilia (2013). “Migración interna indígena desde el Istmo veracruzano: nuevas articulaciones regionales". En LiminaR. Estudios Sociales y Humanísticos, $\mathrm{XI}(2): 128-148$.

Villanueva-Olmedo, Minerva (2011). "La expansión urbana de Xalapa en la primera mitad del siglo XX. Apuntes para la historia de su urbanización". En Ulúa. Revista de Historia, Sociedad y Cultura, 17: 127-158.

\section{Archivos consultados}

Archivo General del Estado de Veracruz (AGEV). Fondo Comisión Agraria Mixta (CAM), expediente 168, Chavarrillo.

Archivo General del Estado de Veracruz (AGEV). Fondo Comisión Agraria Mixta (CAM), expediente 93, Tlalnelhuayocan. 
Foto 1. Cafetal cultivado de la barranca, situada al este de Chavarrillo

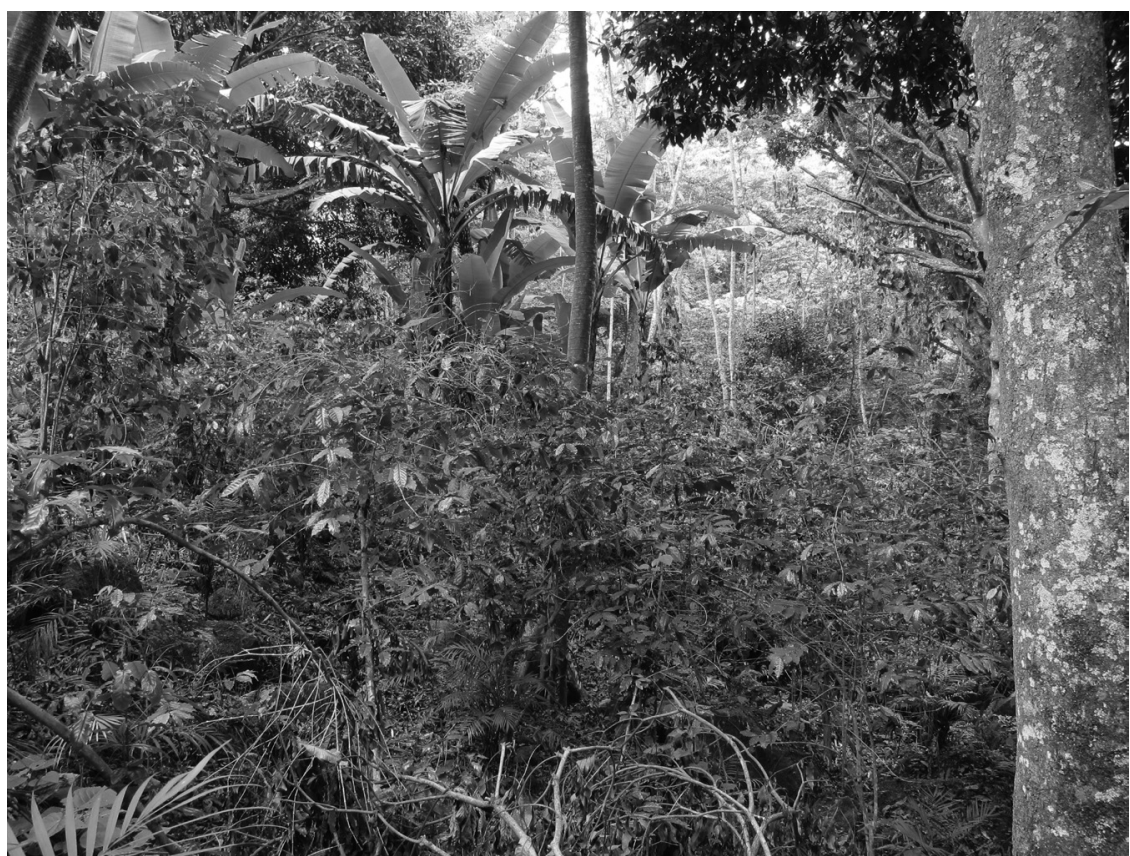

Fuente: Virginie Thiébaut, 28 de junio de 2015.

Foto 2. Combinación de varias actividades agrícolas alrededor de casas habitacionales construidas en una parcela ejidal de Tlalnelhuayocan

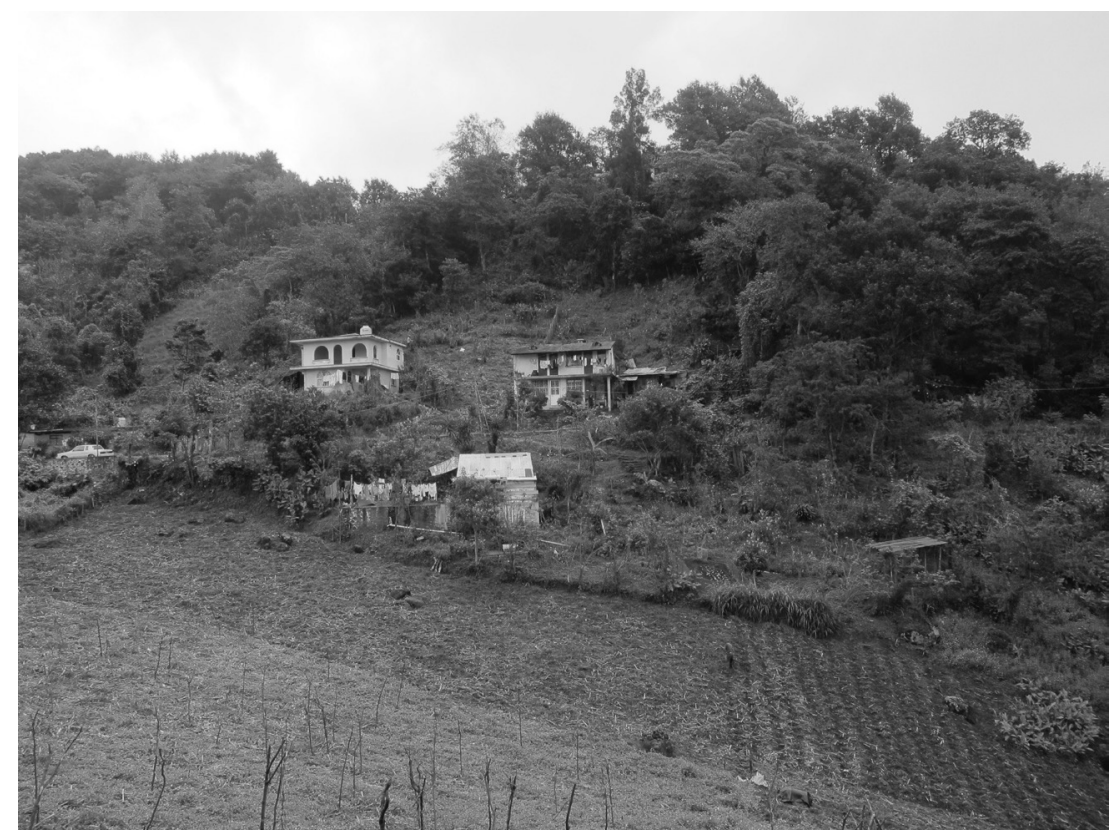

Fuente: Virginie Thiébaut, 8 de diciembre de 2015. 


\section{Mapa 1. Mancha urbana de Xalapa y ubicación de las localidades}
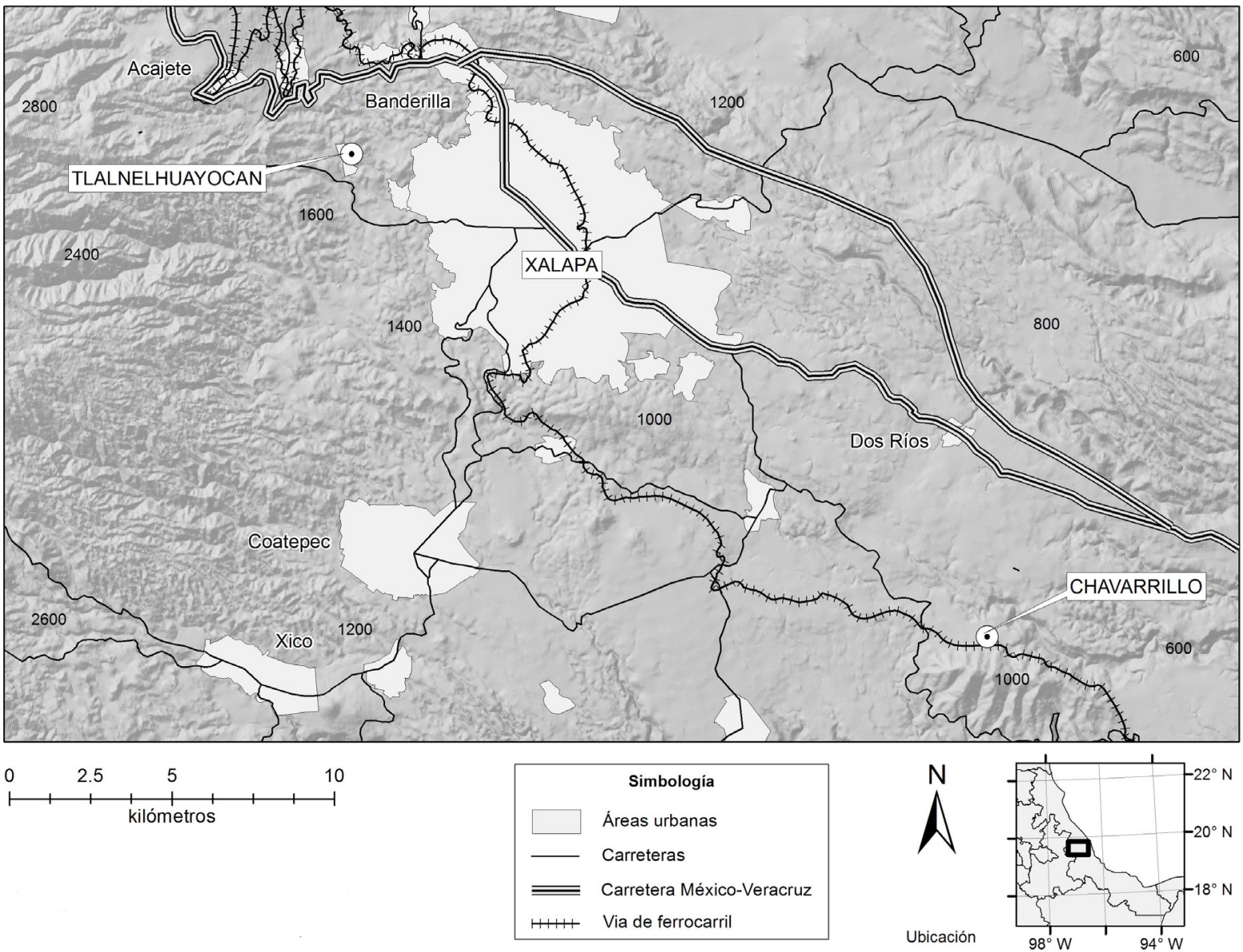

Fuente: mapa elaborado por Paulo César López Romero con datos vectoriales del INEGI (2010), "Delimitación de las zonas metropolitanas de México, 2010". Disponible en: http://www3.inegi.org.mx/sistemas/biblioteca/ficha.aspx?upc=702825003884(c onsultado el 13de agosto de 2015). Nota: los números indican metros sobre el nivel del mar. 